\title{
A STUDY ON BIOLOGICAL FIXATION OF PAEDIATRIC LONG-BONE FRACTURES BY ENDERS NAIL
}

\author{
K. Veeranjaneya Naik1, Ketavath Thulasiram², Nishat Ahmed ${ }^{3}$
}

${ }_{1}^{1}$ Assistant Professor, Department of Orthopaedics, , Government General Hospital, Guntur Medical College, Guntur, Andhra Pradesh, India.

${ }^{2}$ Assistant Professor, Department of Orthopaedics, SVS Medical College, Mahbubnagar, Telangana, India.

3Junior Resident, Department of Orthopaedics, SVS Medical College, Mahbubnagar, Telangana, India.

ABSTRACT
AACKGROUND
like hammer, bone awl twisting guider and hook for extraction. This modality of treatment truly surpasses the need by avoiding
post-operative casting. Early mobilisation prevents joint and muscle stiffness/ contractures and also avoids plaster disuse.

\section{MATERIALS AND METHODS}

A study of 30 patients who had fractures of various long bones in children were undertaken in Guntur Medical College and Government General Hospital, Guntur from May 2012 to April 2014. Cases were selected on the basis of fixed inclusion and exclusion criteria. Study consists of surgical management of various long-bone fractures in children by flexible, multiple Enders nails.

\section{RESULTS}

About $57 \%(n=17)$ belonged to $7-12$ years' age group and 13 cases $(43.3 \%)$ were from $2-6$ years' age group. Two-thirds (n= 20) were males and one-third (10 cases) were females. All the fractures united within 4 months after operation. Anatomical results: Excellent results were obtained in $70 \%$ cases, whereas $16.7 \%$ patients had good anatomical results. $13.3 \%$ patients had fair results. Functional results: Good-to-excellent results were obtained in $86.7 \%$ of patients and $13.3 \%$ patients had fair results.

\section{CONCLUSION}

We were surprised by the versatility of the Enders nailing, as it provides a solution to many fractures that would have been difficult for internal fixation by any other method.

\section{KEY WORDS}

Enders Nailing, Long-Bone Fractures, Children, Fixation.

HOW TO CITE THIS ARTICLE: Naik KV, Thulasiram K, Ahmed N. A study on biological fixation of paediatric long-bone fractures by enders nail. J. Evolution Med. Dent. Sci. 2018;7(47):5069-5075, DOI: 10.14260/jemds/2018/1127
BACKGROUND
Image Intensification (C-ARM) is needed for closed
Approximately, one percent of all fractures in children are femur shaft fractures.[1] The first peak occurs in early childhood and the second in mid-adolescence. Tibial and fibular fractures are the third most common paediatric long- bone injuries (15\%) after femoral and radial/ ulnar fractures. Fractures of the proximal humerus are relatively uncommon injuries of childhood with an incidence of 1.2 to 4.4 per 1,000 per year, fewer than $5 \%$ of all paediatric fractures. ${ }^{[2]}$ common equipment at any orthopaedic hospital. Enders nailing needs minimal instrumentation like hammer, bone awl twisting guider and hook for extraction. Rural population usually prefer conservative management. This modality of treatment truly surpasses the need by avoiding post-operative casting. Early mobilisation prevents joint and muscle stiffness/ contractures and also avoids plaster disuse.

Last few decades has seen increasing trend towards operative management of femoral and tibial shaft fractures in paediatric patients, but opinion regarding optimal method of fixation of these fractures remain divided.[3] External fixation, although producing acceptable results, is fraught with many complications, as is plate osteosynthesis and rigid intramedullary nailing which may also require a second major surgery for removal of implant. $[4,5]$

'Financial or Other Competing Interest': None.

Submission 03-10-2018, Peer Review 30-10-2018,

Acceptance 06-11-2018, Published 19-11-2018.

Corresponding Author:

Dr. Ketavath Thulasiram,

H. No. 8-5-4/C, Teachers Colony,

Mahbubnagar-509001, Telangana, India.

E-mail: tulasi9984@gmail.com

DOI: $10.14260 /$ jemds $/ 2018 / 1127$

\section{Aim and Objective of the Study}

To evaluate the role of Enders nailing in fixing long-bone fractures by minimally invasive technique and biologically fixing long-bone fractures in children aged 2 years to 12 years.

\section{MATERIALS AND METHODS}

A study of 30 patients who had fractures of various long bones in children were undertaken in Guntur Medical College and Government General Hospital, Guntur from May 2012 to April 2014.

Study Design: A hospital-based prospective observational study cases were selected on the basis of a fixed inclusion and exclusion criteria which were devised in the Department of Orthopaedics, Guntur Medical College and Government General Hospital, Guntur.

\section{Inclusion Criteria}

1. Fracture shaft of femur (AO $32 \mathrm{~A}, \mathrm{~B}$ and $\mathrm{C}$ ). 
2. Tibial diaphyseal fractures (AO $42 \mathrm{~A}, \mathrm{~B}$ and $\mathrm{C}$ ).

3. Fracture shaft of humerus (AO $12 \mathrm{~A}, \mathrm{~B}$ and $\mathrm{C}$ ).

4. Compound Fractures upto Gustilo-Anderson Type III B.

5. Patients aged between 2 and 12 years.

\section{Exclusion Criteria}

Patients associated with co-morbid conditions like compartment syndrome.

Study consists of surgical management of various longbone fractures in children by flexible, multiple Enders nails. Case sheet of each patient is prepared as follows.

\section{History}

A detailed history was recorded with particular importance to age, sex, mode of injury, duration of injury, treatment taken (if any), associated medical and surgical illnesses (if any) and the socio-economic status.

\section{Examination}

A thorough general physical examination was undertaken, and condition of the patient assessed by noting the vital signs of pulse, blood pressure, respiration and pallor (if any).

Systemic examination was performed to recognise any preexisting medical and surgical illness, esp. cardiovascular, respiratory or renal disease.

Local examination was conducted to know about the deformity, extent of swelling, local tenderness and abnormal mobility. The neurovascular status was recorded in each case. Limb length was measured, and the amount of shortening was recorded in each case. Any associated injury was recorded, and treatment carried out accordingly. Range of movements was also recorded in each case.

\section{Investigations}

Investigations included haemoglobin, bleeding time, clotting time, complete blood count, urine examination, blood urea, blood sugar and electrocardiogram. X-rays of the affected limb were taken.

\section{Management}

B/K skin traction upto $2 \mathrm{~kg}$ weight for femur, A/K POP slab immobilisation for diaphysis tibia or ' $U$ ' slab immobilisation for humerus applied according to the fracture. Any associated injury or medical or surgical illness was treated accordingly. Patients were operated as early as possible after obtaining anaesthetic fitness.

\section{Apparatus and Instruments}

\section{Enders Nails}

Enders nails are long, slender, flexible intramedullary nails. They are elastic in nature and resist bending stresses. Ranged from 20 to $50 \mathrm{~cm}$ long with range from 2.0 to $4.0 \mathrm{~mm}$ in diameter, in $0.5 \mathrm{~mm}$ increments. During introduction without getting stuck in the bone, whole length of the nail is uniformly cylindrical, solid in cross-section except the distal end which has a flat surface with a hole. This hole side is for removal of the nail and causes less damage to the soft tissues around the ends of the bone. The proximal end is bevelled slightly in order to prevent cortical penetration. The nail is pre-bent along the whole length, especially in the proximal $20 \mathrm{cms}$ at an angle of $120^{\circ}-140^{\circ}$ from the rest of the nail.

\section{Nail Introducer cum Rotator}

It has a slot at its proximal end to accommodate the fit distal end of the nail and has a handle to control rotation of the nail inside the bone.

\section{Nail Impactor}

It also has a slot in its proximal end for impaction, the distal end of the nail in the metaphyseal region.

\section{Nail benders and Nail extractor}

\section{Bone awl and Mallet}

\section{Image intensifier is mandatory}

\section{Anaesthesia}

General anaesthesia or spinal anaesthesia was used depending upon the fitness of the patient. Local anaesthesia supplemented by sedation was in those cases who were not fit for major anaesthesia.

\section{Pre-operative Preparation}

Patient is placed on the operating table and closed reduction of the fracture was obtained by giving simultaneous traction and counter traction in longitudinal direction. The reduction was checked radiologically with image intensifier. Every attempt was made to reduce the fracture by closed means. If closed reduction failed, a small incision was given at the fracture site and reduction achieved. Injectable antibiotic was given preoperatively.

\section{Operative Procedure}

Fixation with Flexible Intramedullary Rods: Technique.

The width of the canal is measured at the narrowest point in the diaphysis on both the AP and lateral views, and this number is divided by 2 . This represents the maximal diameter rod that can be used and generally a rod $0.5 \mathrm{~mm}$ smaller than this radius should be used. Therefore, if the medullary canal measures $8 \mathrm{~mm}$, a $3.5 \mathrm{~mm}$ rod probably should be used, filling approximately $80 \%$ of the canal diameter.

The procedure can be performed on a fluoroscopy table, but reduction must be documented with fluoroscopy before insertion of the rods.

\section{Rod Bending}

The distance from the top of the inserted rod to the level of the fracture site is measured, and a gentle 30-degree bend is placed in the nail with the apex at what will be the level of the fracture. Next the rod tip is bent to facilitate placement and to allow the rod to bounce off the opposite cortex at the time of insertion. This also facilitates spreading of the rods in the proximal metaphysis, either in the femoral neck or in the greater trochanter. Some surgeons prefer to avoid the second bend at the level of the fracture and use these rods as straight rods, much as in traditional intramedullary fixation. Although, not consistent with the recommendation of Lascombes, satisfactory results have been achieved with this technique, especially with the stronger stainless-steel rods. The rods used 
generally are 3.0 to $4.0 \mathrm{~mm}$ in diameter, depending on the size of the bone and the child. Two rods of the same size should always be used, and varying sizes should be avoided.

Entire segment of the involved limb on the injured side was thoroughly scrubbed with Savlon and then painted with betadine and draped, so that only the involved segment of the limb with 2 nearby joints are exposed.

A skin incision approximately $3 \mathrm{cms}$ long was made using image intensifier at the nail insertion site. Subcutaneous tissues are cleared with artery forceps. Periosteum is stripped with periosteal elevator and the bone is exposed. An oval window of size $1 \mathrm{~cm}$ was made in the bone with a curved awl with the long axis in the vertical direction.

\section{Post-Operative Care}

Plaster of Paris immobilisation was given for a period of 3 or more weeks in unstable fractures. Immobilisation with brace was given for stable fractures. Injectable antibiotics was given for three days followed by oral broad-spectrum antibiotics for seven days. Sutures were removed on 9 th or 10th postoperative day. Boot and bar was applied in two cases (Intertrochanteric fractures) and was continued for 3 weeks.

\section{Physical Therapy}

Stable Fractures: Static muscle strengthening exercises were started from the first post-operative day. Patients were allowed to walk with crutches after suture removal or after 2 weeks and gradually full weight bearing was allowed at 4 to 6 weeks after surgery. For humerus fractures, patients were allowed to take shoulder and elbow mobilisation exercises after 2 weeks.

\section{Unstable Fractures}

Static muscle strengthening exercises were started from the next day of surgery. Patients were allowed non-weight bearing crutch walking for 4 to 6 weeks and then gradually full weight bearing was allowed depending upon the patient and tolerance.

\section{Follow-Up}

Patients were followed at regular intervals for at least 10 to 12 months and all the patients were examined clinically for any evidence of wound infection, deformity and range of movements at two nearby joints, limb length discrepancy, malalignment, knee and shoulder stiffness and ability to squat. Radiological examination was carried out for evidence of union and migration of nails.

\section{Post-Operative Status}

Post-Operative Cases are followed as Described Below

- $\quad$ Check x-rays of the bone and 2 nearby joints- AP and Lat.

- Physiotherapy started on.

- Movements of the joints started on.

- Partial weight bearing started on.

- Full weight bearing started on.

\section{Follow-Up Protocol}

\section{Clinical}

- $\quad$ Pain (Mild/Mod/Severe/Nil).

- $\quad$ Shortening was compared with normal limb in cms.

- Rotational malalignment (In Degrees).

- $\quad$ Range of movement joint active and passive (In Degrees).
- Wound infection (if any).

- Knee stiffness (if any).

- $\quad$ Shoulder stiffness (if any).

\section{Radiological}

- Evidence of fracture union.

- Disimpaction (if any) in AP and L at planes.

- Nail penetration and migration.

\section{Evaluation of Results}

Results were evaluated both anatomically and functionally according to the following criteria.

\section{Anatomical}

Excellent: No shortening or deformity, clinically or radiologically.

Good: Upto $2 \mathrm{cms}$ shortening. No rotational deformity.

Fair: 2 to $4 \mathrm{cms}$ shortening. Slight rotational deformity.

Poor: More than $4 \mathrm{cms}$ shortening. Obvious rotational deformity.

\section{Functional}

Excellent: Full range of joint movements. No disability.

Good: Slight limitation (10 - 20\%) of joint movements. Other disability hardly appreciable.

Fair: Considerable limitation (20 - 50\%) of joint movements. Mild-to-Moderate disability.

Poor: More than $50 \%$ limitation of joint movements. Moderate-to-Severe disability.

\section{Statistical Analysis}

Data entry and analysis was done using Microsoft Excel 2010 version. Data was presented in percentages.

\section{RESULTS}

The present case series includes 30 patients of age between 212 years of age group with of long-bone diaphyseal fractures in children managed surgically by intramedullary flexible nailing technique. All the cases were managed in the Department of Orthopaedics, Guntur Medical College and Government General Hospital, Guntur during the period from May 2012 to April 2014.

Age and Sex Distribution: About 57\% $(n=17)$ belonged to 7 - 12 years' age group and 13 cases (43.3\%) were from 2 - 6 years' age group. Two-thirds $(n=20)$ were males and one-third (10 cases) females.

Majority (63.3\%, $\mathrm{n}=17$ cases) involved on right side and thirteen cases involved on left side.

The common mode of injury was Road Traffic Accident in $63.3 \%$ ( 19 cases). $36.7 \%$ of the patients due to slip and fall in the present study. Most of the patients reported to the hospital on the day of injury (76.7\%).

Associated Injuries: 2 cases only, one with opposite distal femur fracture and another with ipsilateral both bones forearm fracture, i.e. $6.7 \%$.

With regards to interval between injury and operation $76.7 \%$ of the cases were operated within 7 days of injury, whereas only $23.3 \%$ of the patients could be operated within 7 - 14 days of injury. 


\section{Operative Details}

$86.7 \%$ of the fractures were operated under general anaesthesia, $13.3 \%$ under spinal anaesthesia. In half the cases (15), duration of operation was 31 - 40 minutes followed by $43.3 \%$ who had 41 - 50 minutes duration. $73.3 \%$ of the patients had less than $50 \mathrm{~mL}$ blood loss during operation. Average blood loss was $40 \mathrm{~mL}$.

Almost two-thirds (63.3\%) had 8 - 14 days of hospital stay followed by 10 cases that stayed for about $15-21$ days. None of the patients were discharged within seven days following surgery.

\section{Ambulatory Status}

$20 \%$ of the patients were able to bear full weight by the end of 6 weeks where as $80 \%$ of the patients were able to bear full weight by the end of 12 weeks post-operatively.

\section{Incidence of Union}

All the fractures united within 4 months after operation.

\section{Anatomical Results}

Excellent results were obtained in $70 \%$ cases, whereas $16.7 \%$ patients had good anatomical results. $13.3 \%$ patients had fair results.

\section{Functional Results}

Good-to-excellent results were obtained in $86.7 \%$ of patients and $13.3 \%$ patients had fair results.

\section{Complications}

The complications observed were shortening which was seen in 1 case. Slight-to-considerable limitation of joint movements were seen in 4 patients. In the present study, there were no cases of infection. No patient died during the post-operative period. None of the cases reported any complications like migration of nail, infection, bed sores and implant failure. None of them required any secondary procedure.

\begin{tabular}{|c|c|c|}
\hline Anatomical Results & No. of Cases & Percentage \\
\hline Excellent & 21 & 70 \\
\hline Good & 5 & 16.7 \\
\hline Fair & 4 & 13.3 \\
\hline Poor & - & - \\
\hline Total & $\mathbf{3 0}$ & $\mathbf{1 0 0} \%$ \\
\hline \multicolumn{2}{|c|}{ Table 1. Anatomical Results } \\
\hline
\end{tabular}

\begin{tabular}{|c|c|c|}
\hline Functional Results & No. of Cases & Percentage \\
\hline Excellent & 21 & 70 \\
\hline Good & 5 & 16.7 \\
\hline Fair & 4 & 13.3 \\
\hline Poor & 0 & 0 \\
\hline Total & $\mathbf{3 0}$ & $\mathbf{1 0 0} \%$ \\
\hline \multicolumn{2}{|c|}{ Table 2. Functional Results }
\end{tabular}

\begin{tabular}{|c|c|c|}
\hline Complications & $\begin{array}{c}\text { No. of } \\
\text { Cases }\end{array}$ & $\mathbf{\%}$ \\
\hline 1. Shortening < $2 \mathrm{~cm}$ & 2 & $6.7 \%$ \\
\hline 2. Malunion with rotational deformity & 1 & $3.3 \%$ \\
\hline 3. Limitation of joint movements (total) & 6 & 20 \\
\hline a) Slight (10 - 20\%) & 4 & $13.3 \%$ \\
\hline b) Considerable (20 - 50\%) & 1 & $6.7 \%$ \\
\hline c) More than 50\% & - & - \\
\hline Table 3. Complications & \\
\hline
\end{tabular}

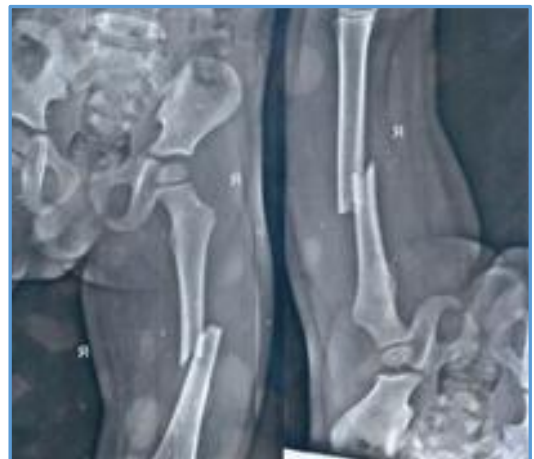

Figure 1.1. Pre-op X-ray

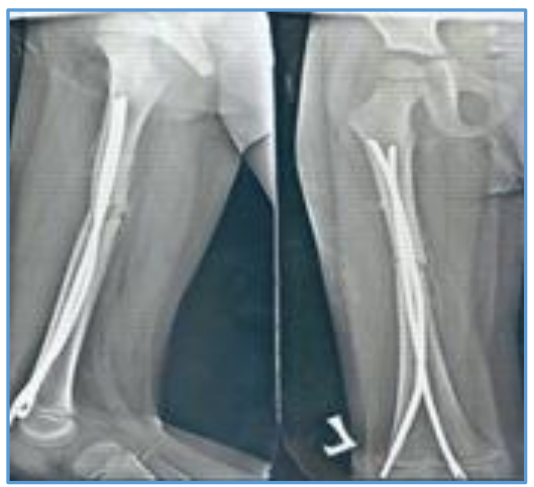

Figure 1.2. Immediate Post-op

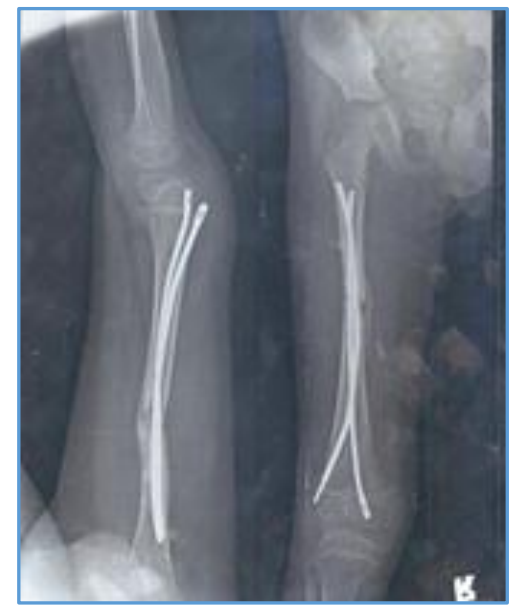

Figure 1.3. 3 Months Post-op

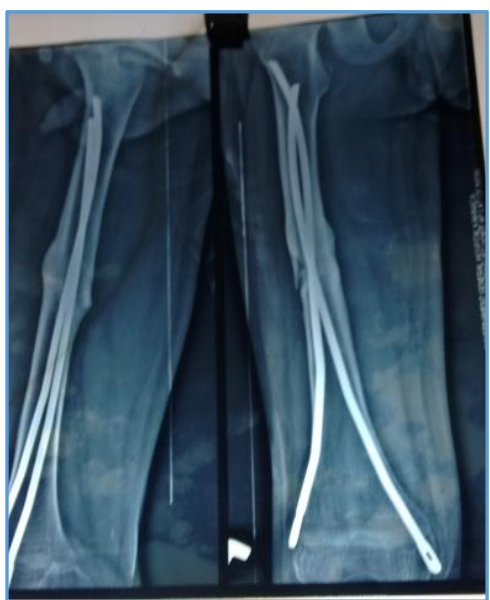

Figure 1.4. 6 Months Post-op 


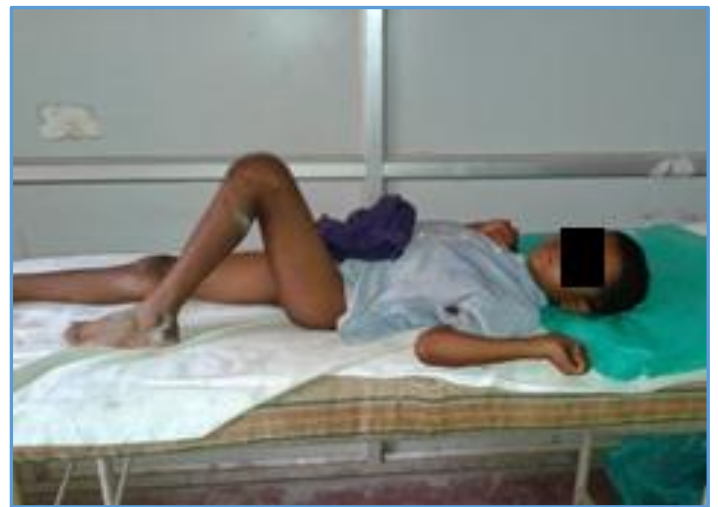

Figure 1.5. Straight Leg Raising

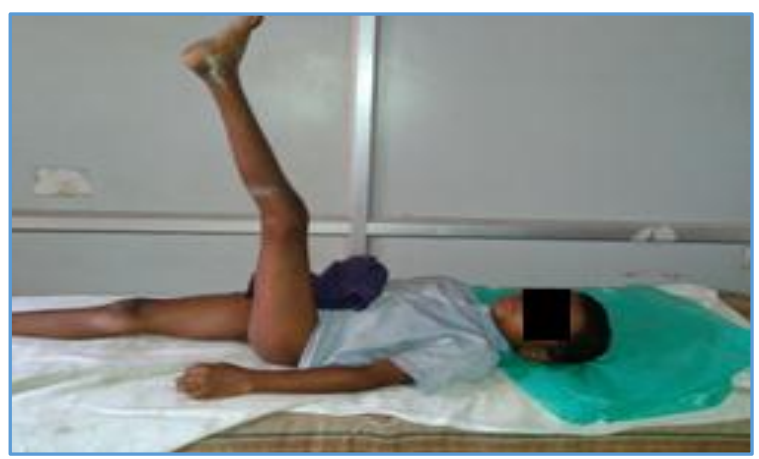

Figure 1.6. Knee and Hip Flexion

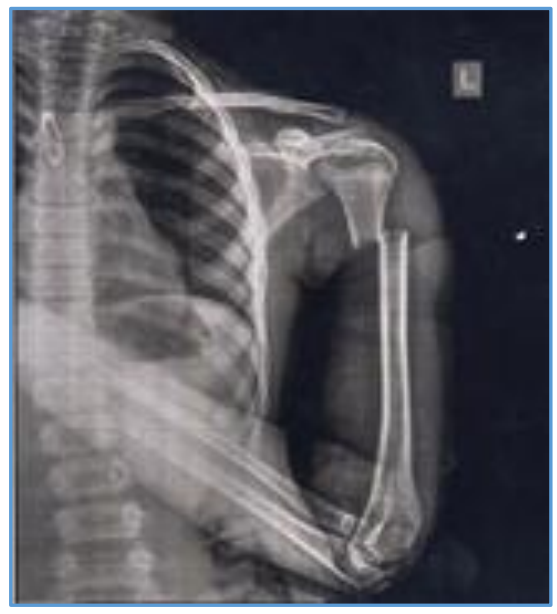

Figure 2.1. Pre-op X-ray

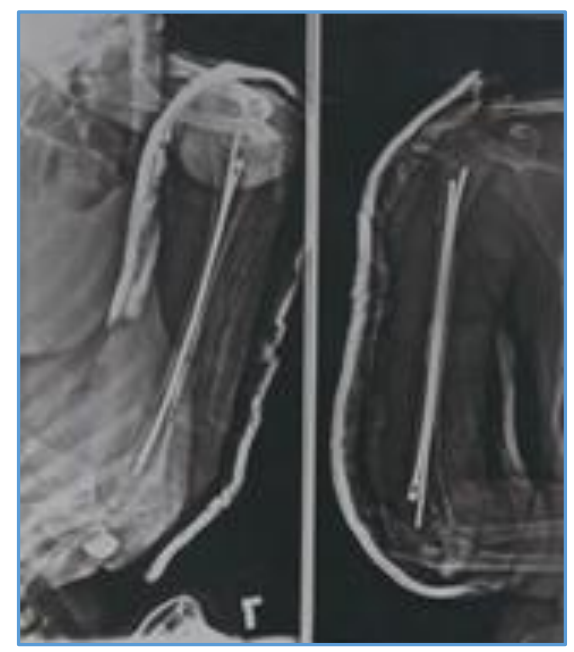

Figure 2.2. Immediate Post-op

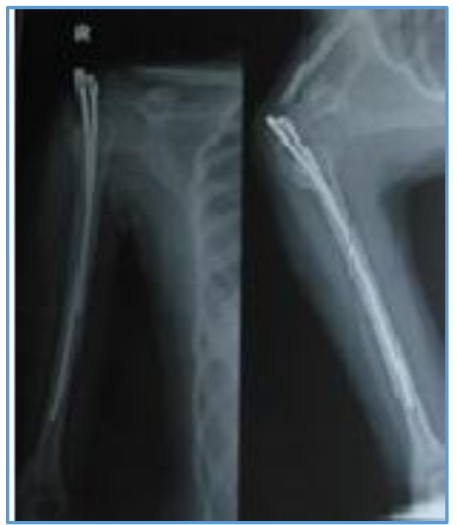

Figure 2.3. 2 Months Post-op

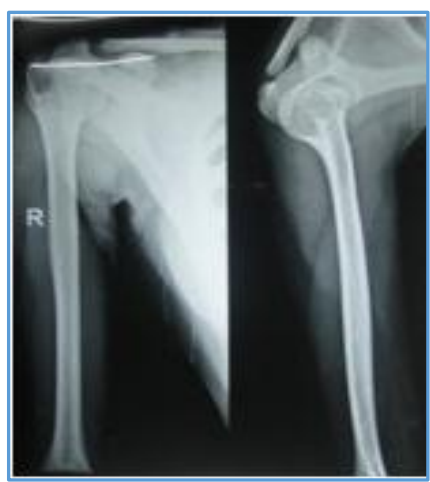

Figure 2.4. 12 Months Post-op

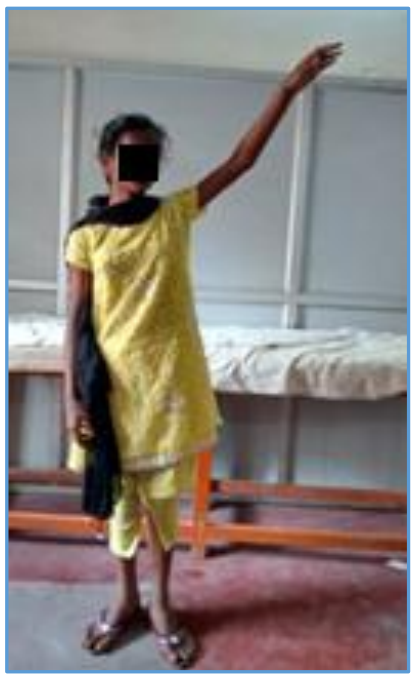

Figure 2.5. Above Head Abduction

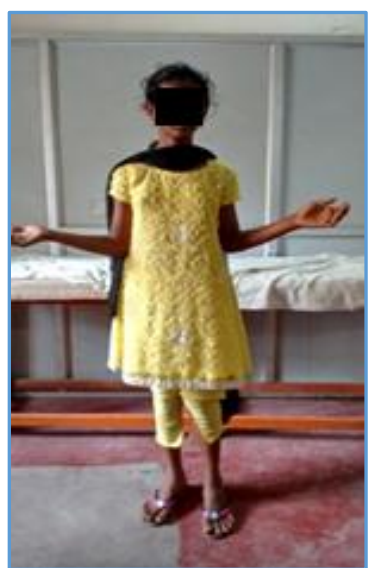

Figure 2.6. External Rotation 


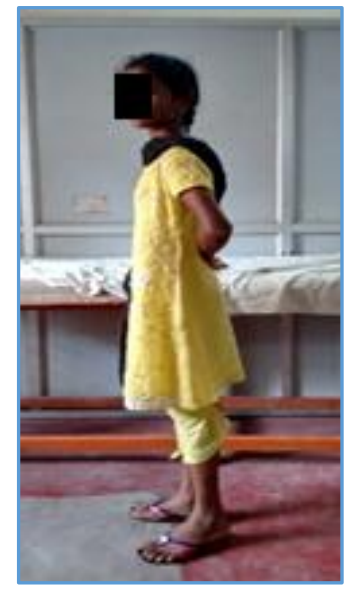

Figure 2.7. Internal Rotation

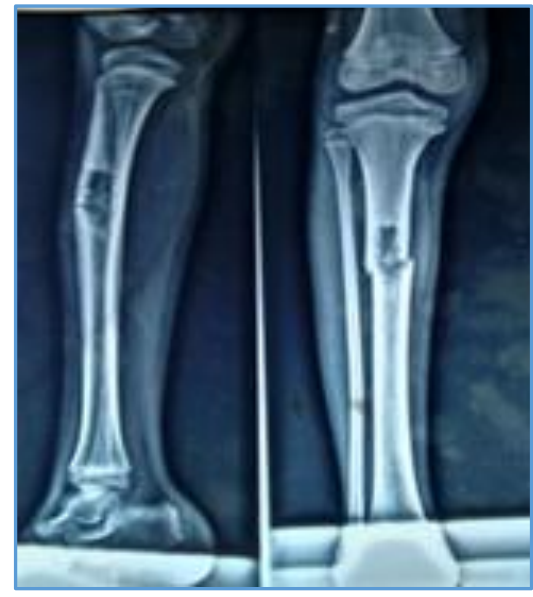

Figure 3.1. Pre-op

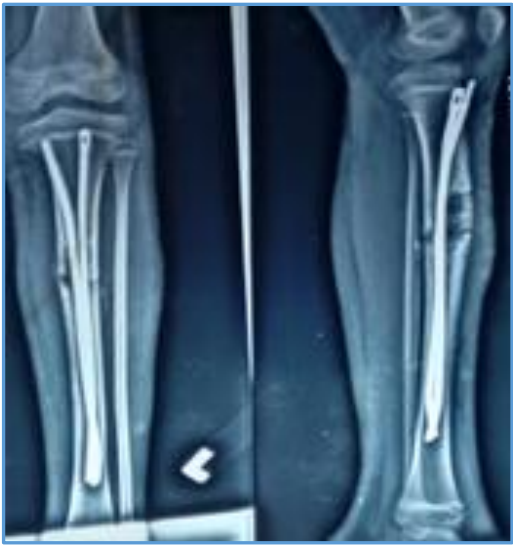

Figure 3.2. Immediate Post-op

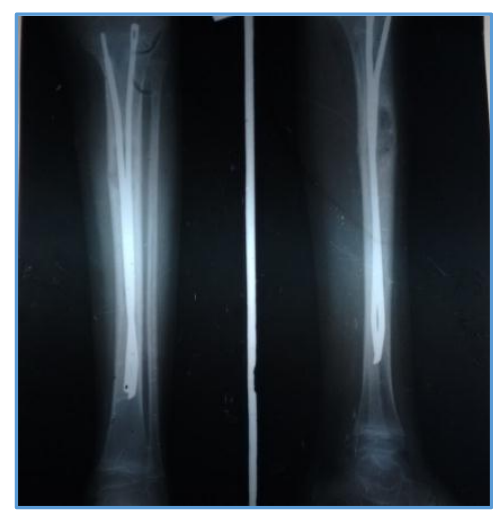

Figure 3.3. 3 Months Post-op

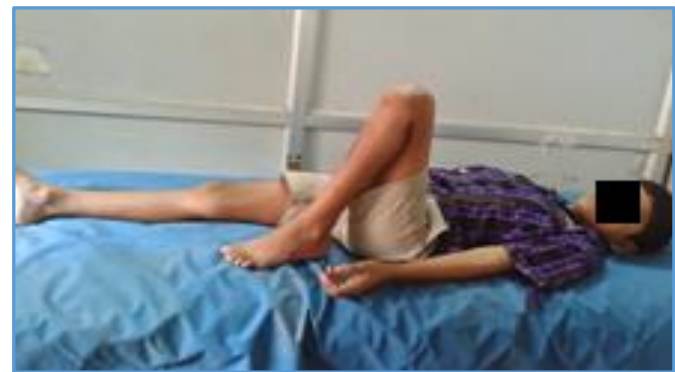

Figure 3.4. Knee Flexion

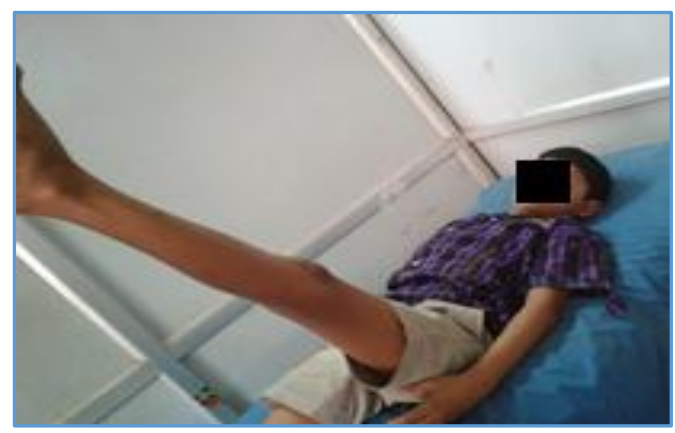

Figure 3.5. Knee Extension

\section{DISCUSSION}

The growing child has an astonishing ability to remodel its bones and in many cases will wipe out the evidence of a malunited fracture. It is probably fair to say that we are guilty of placing undue reliance on this phenomenon when poor conservative management results in deformity or shortening at the fracture site.

\section{Age Distribution}

In the present study, patients between 2 and 12 yrs. of age were included. Average age was 7.5 yrs. Ozturkmen et al[6] reported average age of 8.9 yrs. (5.9 - 12.3 yrs.). Kalenderer et al[7] showed average age of 10 yrs. (7 - 15 yrs.). Present study includes per school age group between $2-6$ yrs., which was previously considered as optimal group for conservative management.

\section{Sex Distribution}

The present study reports $20(66.66 \%)$ diaphyseal fractures occurring in male children as compared to 10 in females $(33.33 \%)$. In most of the series, there is male predominance. Ozturkmen et al[6] reported out of 26 children, there were 19 male and 7 female children. Kalenderer et al[7] reported 17 boys and 3 girls in total of 20 cases. Higher incidence of male patients in our study may be due to social factors and girls are less active than boys, so less exposed to risk of injury while playing.

In the current study most of the cases operated within 7 days of injury (76.66\%), whereas Chan et al[8] in 1982 reported that 72 percent of patients were operated within 3 days of injury. This difference is primarily due to large number of emergencies due to over population, relative scarcity of beds in wards and time taken for assessment of operative fitness.

Average time taken for radiological union in the present study was 7.3 weeks. Ozturkmen et al[6] reported 6.6-week average period for union (6 - 12 weeks). Heybeli et al[9] reported average 7.4 weeks (5 - 12 weeks) for union. Oh et al[10] reported average 10.5 weeks for union. 
However, Passoff and Schein ${ }^{[11]}$ reported that 100 percent of fractures united within 4 months. Pankovich and Tarabishy[12] reported a 96 percent incidence of union in 12 weeks. Chan et al[8] reported that all fractures united in 10-12 weeks. There was no case of delayed or non-union in our series as was also reported by Chan et al,[8] Iwegbu and Patel[13] and Passoff and Schein.[11]

Flexible nailing for paediatric femoral shaft fractures has yielded predictably excellent union across the literature. Ligier et al reported union in all 123 cases treated with this technique.[14] Flynn et al[15] and Narayanan et al[3] also did not report any union difficulties. Luhmann et al[16] observed one hypertrophic non-union in 43 treated femoral shaft fractures. In our study, average time for union was 8 weeks $(6-12$ weeks).

\section{CONCLUSION}

Enders nailing is ideally suited not only for the children and younger age groups, but also in biologically old, fragile, high anaesthesia risk and osteoporotic patients-

Hence, it can aptly be called as "Friendly to Paediatric, Geriatric and Younger Age Groups."

- This method is less traumatic, gentle and one of the simplest methods known.

- This method is based on sound biomechanical principles. The intramedullary position of the implant places it more in line with the weight bearing forces, thereby reducing the tendency of the fracture to settle in a deformed position.

The excellent biomechanics is reflected by the absence of implant failure. No case of delayed or non-union in the present study.

Early ambulation is one of the advantages of the Enders nailing. This helps to minimise the duration of hospital stay and complications of enforced bed rest like pneumonias, bed sores, UTI, thromboembolic phenomenon, etc.

The risk of infection is negligible, as the incision is far away from the Fracture. The high incidence of complications in unstable fractures necessitates a certain degree of caution to be exercised. Few weeks' protection often required postoperatively.

Nails are low cost and many people in developing countries and underdeveloped countries can afford them. Operative time is also less. This is also very useful in overpopulated countries. Patients are more comfortable from 1st post-operative day onwards, because of its least traumatic nature. In segmental fractures, Enders nailing eliminates the torsion of the middle segment, so chances of necrosis of the middle segment is minimised.

Finally, we were surprised by the versatility of the Enders nailing, as it provides a solution to many fractures that would have been difficult for internal fixation by any other method.

\section{REFERENCES}

[1] Scherl SA, Miller L, Lively N, et al. Accidental and nonaccidental femur fractures in children. Clin Orthop Relat Res 2000;(376):96-105.

[2] Hedstrom EM, Svensson O, Bergstrom U, et al. Epidemiology of fractures in children and adolescents. Acta Orthop 2010;81(1):148-53.

[3] Narayanan UG, Hyman JE, Wainwright AM, et al. Complications of elastic stable intramedullary nail fixation of pediatric femoral fractures and how to avoid them. J Pediatr Orthop 2004;24(4):363-9.

[4] Sponseller PD. Surgical management of pediatric femoral fractures. Instr Course Lect 2002;51:361-5.

[5] Mostafa M, Hassan M, Gaballa MA. Treatment of femoral shaft fractures in children and adolescents. J Trauma 2001;51(6):1182-8.

[6] Ozturkmen Y, Dogrul C, Balioglu MB, et al. Intramedullary stabilization of pediatric diaphyseal femur fractures with elastic Enders nail. Acta Orthop Traumatol Turc 2002;36(3):220-7.

[7] Kalenderer 0, Agus H, Sanli C. Open reduction \& intramedullary fixation through minimal incision with Ender nails in femoral fractures of children aged from 6 to 16 yrs. Acta Orthop Traumatol Turc 2002;36(4):3039.

[8] Chan KM, Chow YN, Leung PC. Treatment of trochanteric fractures with Ender's nailing in Chinese patients. Injury 1982;13(6):464-72.

[9] Heybeli M, Muratli HH, Celebi L, et al. The results of intramedullary fixation with titanium elastic nails in children with femoral fractures. Acta Orthop Traumatol Turc 2004;38(3):178-87.

[10] Oh CW, Park BC, Kim PT, et al. Retrograde flexible intramedullary nailing in children's femoral fractures. Int Orthop (Sicot) 2002;26(1):52-5.

[11] Passoff TL, Schein AJ. Ender's flexible intramedullary pins for the treatment of pertrochanteric hip fractures: preliminary report of the first 100 cases. J Trauma 1980;20(10):876-9.

[12] Pankovich AM, Tarabishy IE. Ender nailing of intertrochanteric and subtrochanteric fractures of the femur. J Bone Joint Surg Am 1980;62(4):635-45.

[13] Iwegbu CG, Patel RJ. Difficulties and complications of the Ender method of treatment of trochanteric fractures of the femur. Injury 1981;13(2):116-24.

[14] Ligier JN, Metaizeau JP, Prévol J, et al. Elastic stable intramedullary nailing of femoral shaft fractures in children J Bone Joint Surg Br 1988;70(1):74-7.

[15] Flynn JM, Hresko T, Reynolds RA, et al. Titanium elastic nails for pediatric femur fractures: a multicenter study of early results with analysis of complications. J Pediatr Orthop 2001;21:4-8.

[16] Luhmann SJ, Schootman M, Schoenecker PL, et al. Complications of titanium elastic nails for pediatric femoral shaft fractures. J Pediatr Orthop 2003;23(4):443-7. 